\title{
Agrophysical Symbology: A New Handbook for Soil Scientists ${ }^{1}$
}

\author{
I. I. Karmanov \\ Dokuchaev Soil Science Institute, per Pyzhevskii 7, Moscow, 119017 Russia \\ Received February 10, 2009
}

DOI: $10.1134 / \mathrm{S} 1064229309110155$

The book under review is devoted to symbols and abbreviations used in soil agrophysics. It is aimed at helping soil scientists to read Russian and foreign literature in the field of agrophysics.

The first draft of the system of symbols applied in agrophysical investigations was prepared by Il'in in 1977 and reported at the V All-Union Soil Science Congress in Minsk. The author continued working on this draft with due account for the critical remarks expressed by his colleagues. At present, this work has been presented in its complete form.

The development of science is accompanied by the development and refinement of its terminology: new terms appear, and old terms get more accurate definitions. The author of this book is known for his works in soil physics; in particular, he studied the influence of different physical parameters of irrigated soils on water consumption by plants. Soil scientists specializing in reclamation works use different terms to define the water consumed by plants: productive water, available water, active water, efficient water, etc. However, no exact definitions of these terms exist in soil science. The author suggests a system of adequate definitions for these terms and their use.

Overall, the system of symbols, indices, and abbreviations includes 34 abbreviations, 26 major elements of different symbols, 107 indices, and 249 symbols. It is based on eight principles.

(1) The use of Russian-based abbreviations in texts, and the use of English-based symbols in various equations.

(2) A unified construction of all the symbols.

(3) Each symbol has its own linguistic basis.

(4) The number of letters in the symbols is minimized.

\footnotetext{
${ }^{1}$ Il'in, I.R., Agrofizicheskaya simvolika (Agrophysical Symbology), Tiraspol: Litera, 2007, 74 pp. [in Russian].
}

(5) Similar kernels are used for groups of closely related symbols.

(6) Only one letter is used as the kernel of each symbol.

(7) The recommendations of the International Organization for Standardization and the IUSS Commission on Terminology in Soil Physics should be taken into account.

(8) The preservation, if possible, of the traditional symbols that have been used in soil science literature.

In many sciences, the terminology is a weak point. Often, similar terms are used to designate different objects and phenomena and, vice versa, different terms may be used to designate similar phenomena. Before the publication of the book by Il'in, a similar situation took place in soil agrophysics.

Il'in has reviewed all the terms used in agrophysics and systematized them.

He has excluded the ambiguity in using the terms; each object and phenomenon has got its own clear definition and an appropriate term. The list of the symbols used has been considerably expanded; new symbols have been introduced. English-based symbols have been applied in the system to ease the reading of English texts. Finally, Il'in has suggested a comprehensive system for developing letter-based symbols with a combination of two-four letters in subscripts and superscripts.

In fact, the practical use of this book is complicated by the great number of symbols that cannot be memorized. It is feasible to have it on one's desktop as a valuable handbook. From my point of view, some of the suggested symbols could be omitted because of their rare use in soil agrophysics.

In general, the new book by I.R. Il' in is a significant contribution to soil agrophysics and the related fields of soil science. 